\title{
An Investigation of the Relationship between Risk and Return: The Case of the Latin American Stock Markets
}

\author{
Chikashi Tsuji ${ }^{1}$ \\ ${ }^{1}$ Faculty of Economics, Chuo University, Tokyo, Japan \\ Correspondence: Chikashi Tsuji, Faculty of Economics, Chuo University, 742-1 Higashinakano Hachioji-shi, Tokyo \\ 192-0393, Japan. Tel: 81-42-674-2211. E-mail: mail_sec_low@minos.ocn.ne.jp
}

Received: December 12, 2013

Accepted: December 24, 2013

Online Published: December 30, 2013

doi:10.5430/afr.v3n1p9

URL: http://dx.doi.org/10.5430/afr.v3n1p9

\begin{abstract}
This paper empirically explores the time-varying risk and return relationship in the Latin American equity markets. Our investigations find some positive linkage between risk and return in Latin America although it does not always perfectly hold. More concretely, first, we find that in the Latin American stock markets, in the daily and quarterly data, positive relationship between risk and return is relatively often observed although it is not always recognized. Second, we find that in Brazilian and Colombian equity markets, positive relations between risk and return are relatively often observed. On the other hand, from our investigations, in the stock markets in Chile, no positive risk-return tradeoff is observed.
\end{abstract}

Keywords: EGARCH-in-mean model, GARCH-in-mean model, Latin American stock markets, Risk-return tradeoff, Time-varying volatility

\section{Introduction}

Risk-return tradeoff is the central concern in the world of standard finance. In the markets of some countries in Latin America, the time-series trends are generally upward recently; thus it is natural to consider that the positive risk-return tradeoff is observed in the recent Latin American equity markets. Based on this prediction, it shall be meaningful to analyze recent stock market data of several countries in Latin America even if their sample periods are not necessarily long enough.

There are preceding studies that investigated the risk-return tradeoff in the US. These are researches by French et al. (1987), Ghysels et al. (2005), and Lundblad (2007), which documented the positive linkage between risk and return. On the other hand, Baillie and DeGennaro (1990) and Glosten et al. (1993) insisted that there were negative relations between risk and return. In addition, studies by Campbell (1987), Harvey (1991), and Whitelaw (1994) evidenced the mixed relations between them. Although there are many researches on this matter in the US as reviewed above, however, there seem to be little empirical examination on this issue by utilizing the recent upward Latin American stock market data.

Thus based on these research backgrounds, the objective of this paper is to empirically examine the time-varying linkage between risk and return in some countries' stock markets in Latin America. In our investigations, we use the daily, weekly, monthly, and quarterly data. This is also one of the favorable characteristics of this study. The interesting findings of this study are as follows. First, we find that in the Latin American equity markets, in the daily and quarterly data, positive linkage between risk and return is relatively often observed although it is not always recognized. Second, we reveal that in the equity markets of Brazil and Colombia, positive relations between risk and return are relatively often observed although it does not always hold either. On the other hand, in the stock markets in Chile, no positive risk-return relationship is observed. The rest of the paper is organized as follows. Section 2 documents our several discussions, Section 3 explains our data and methodology, Section 4 displays our empirical results, and Section 5 summarizes the paper with some perspectives.

\section{Discussion}

This section discusses several important points to consider the risk-return tradeoff of stock returns. (1) First are regarding the trends of markets. In markets of the countries in Latin America, the stock price trends are generally upward recently; thus naturally, there would be higher possibility that the positive risk-return tradeoff is observed in the recent Latin American equity markets. (2) Second is the data time period: it is important to analyze the long-term 
data generally, however, from more practical point of view, our concern often lies in the states of recent and future market dynamics. Hence it shall be meaningful to analyze recent market data even if their sample periods are not so long enough. (3) Third is the data frequency: we consider that in existing studies, several data frequencies were not simultaneously analyzed regardless of the importance of the data frequency. For example, in practice, even if the risk-return tradeoff is observed in daily data, it may be neither highly useful nor significant for institutional investors. Thus it is favorable for us to analyze the data of several frequencies simultaneously. (4) Fourth is the model specification. Namely, we consider that analyzing by using several kinds of econometrical models is important for judging the states of the real-world equity markets. In general, the more complicated the models become, the higher the so-called model risk is, thus generally, it may be difficult to judge the real states of the risk-return relationship in equity markets when we use more complicated models. Therefore, we shall analyze stock return data by using several kinds of models.

In order to derive some answers to the above questions, we should perform careful empirical analyses by considering several issues discussed above. Hence from the next section, we describe the data and empirical methodologies used in this paper.

\section{Data and Methodology}

In this study, we use four kinds of time-series stock return data of the countries in Latin America. The countries include Brazil, Chile, Colombia, and Mexico, and our sample period spans from June 2001 to November 2013. More specifically, the stock returns data are computed from the Morgan Stanley Capital Index (MSCI, dividends included and local currency base), and these data are supplied by the Quick Corp. In addition, our daily data sample period is from 21 June 2001 to 26 November 2013; our weekly data sample period is from the final week of June 2001 to the final week of November 2013; our monthly data sample period is from June 2001 to November 2013; our quarterly data sample period is from the third quarter of 2001 to the fourth quarter of 2013. We exhibit the descriptive statistics for our four kinds of stock returns as to four countries in Latin America in Table 1. In addition, we show the daily dynamics of the MSCI stock index prices of the above four countries in Latin America in Figure 1.

Next, for testing the risk-return tradeoff in the recent Latin American stock markets, we employ four kinds of GARCH-in-mean models. The first model is the following GARCH-in-mean $(1,1)$ model including the conditional variance in its mean equation as follows:

$$
\begin{aligned}
& R E T_{i, t}=\eta_{i, 0}+\eta_{i, 1} \sigma_{i, t}^{2}+v_{i, t}, \\
& \sigma_{i, t}^{2}=\tau_{i, 0}+\tau_{i, 1} \sigma_{i, t-1}^{2}+\tau_{i, 2} v_{i, t-1}^{2} .
\end{aligned}
$$

In model (1), the variable $R E T_{i, t}$ denotes the return of country $i$ at time $t$ and the variable $\sigma_{i, t}$ denotes the return volatility at time $t$.

Our second model is the following GARCH-in-mean $(1,1)$ model including the conditional standard deviation in its mean equation as follows:

$$
\begin{aligned}
& R E T_{i, t}=\varsigma_{i, 0}+\varsigma_{i, 1} \sigma_{i, t}+\omega_{i, t}, \\
& \sigma_{i, t}^{2}=\mu_{i, 0}+\mu_{i, 1} \sigma_{i, t-1}^{2}+\mu_{i, 2} \omega_{i, t-1}^{2} .
\end{aligned}
$$

Again, $R E T_{i, t}$ in model (2) denotes the return of country $i$ at time $t$ and $\sigma_{i, t}$ in model (2) denotes the return volatility at time $t$.

Further, our third model is the following EGARCH-in-mean $(1,1)$ model including the conditional variance in its mean equation as follows:

$$
\begin{gathered}
\operatorname{RET}_{i, t}=\xi_{i, 0}+\xi_{i, 1} \sigma_{i, t}^{2}+\varepsilon_{i, t}, \\
\ln \left(\sigma_{i, t}^{2}\right)=v_{i, 0}+v_{i, 1} \ln \left(\sigma_{i, t-1}^{2}\right)+v_{i, 2}\left(\left|\varepsilon_{t-1} / \sigma_{i, t-1}\right|\right)+v_{i, 3}\left(\varepsilon_{t-1} / \sigma_{i, t-1}\right) .
\end{gathered}
$$

In the above model (3), variable notations are the same as those of the models (1) and (2).

Finally, our fourth model is the following EGARCH-in-mean $(1,1)$ model including the conditional standard deviation in its mean equation as follows:

$$
\begin{gathered}
R E T_{i, t}=i_{i, 0}+t_{i, 1} \sigma_{i, t}+\kappa_{i, t}, \\
\ln \left(\sigma_{i, t}^{2}\right)=\varphi_{i, 0}+\varphi_{i, 1} \ln \left(\sigma_{i, t-1}^{2}\right)+\varphi_{i, 2}\left(\left|\kappa_{t-1} / \sigma_{i, t-1}\right|\right)+\varphi_{i, 3}\left(\kappa_{t-1} / \sigma_{i, t-1}\right) .
\end{gathered}
$$

In the above model (4), variable notations are the same as those of the models (1) and (2). 
Panel A. Brazil

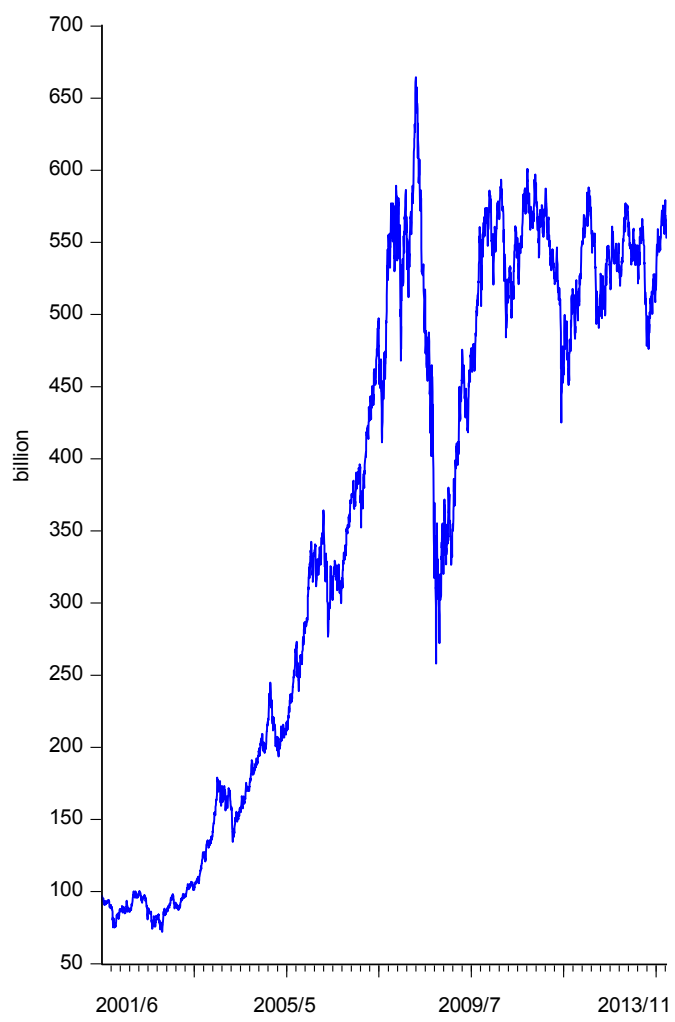

Panel C. Colombia

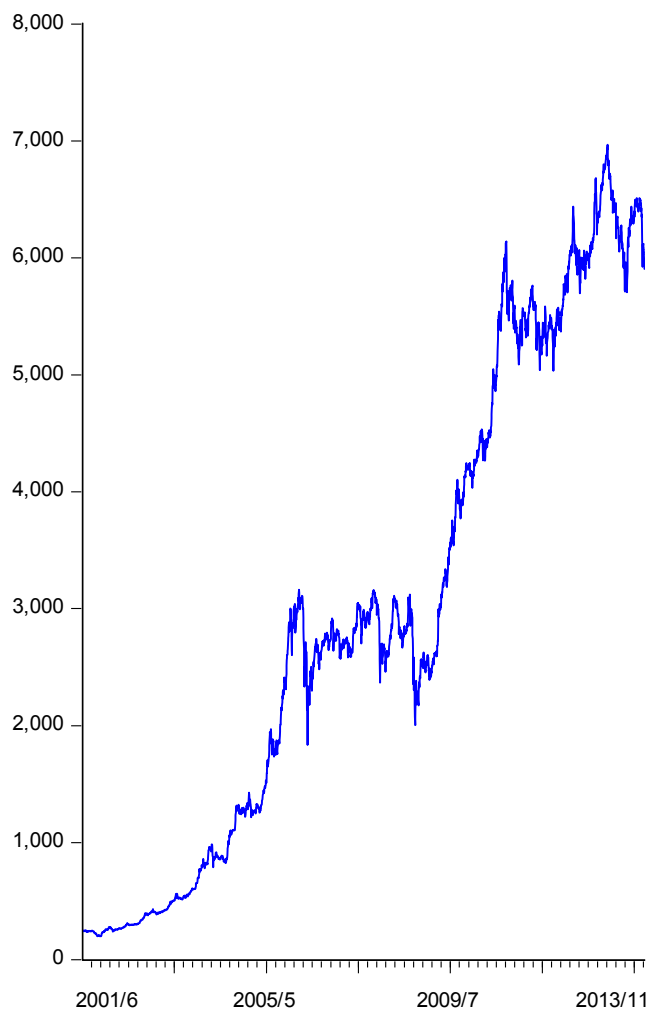

Panel B. Chile

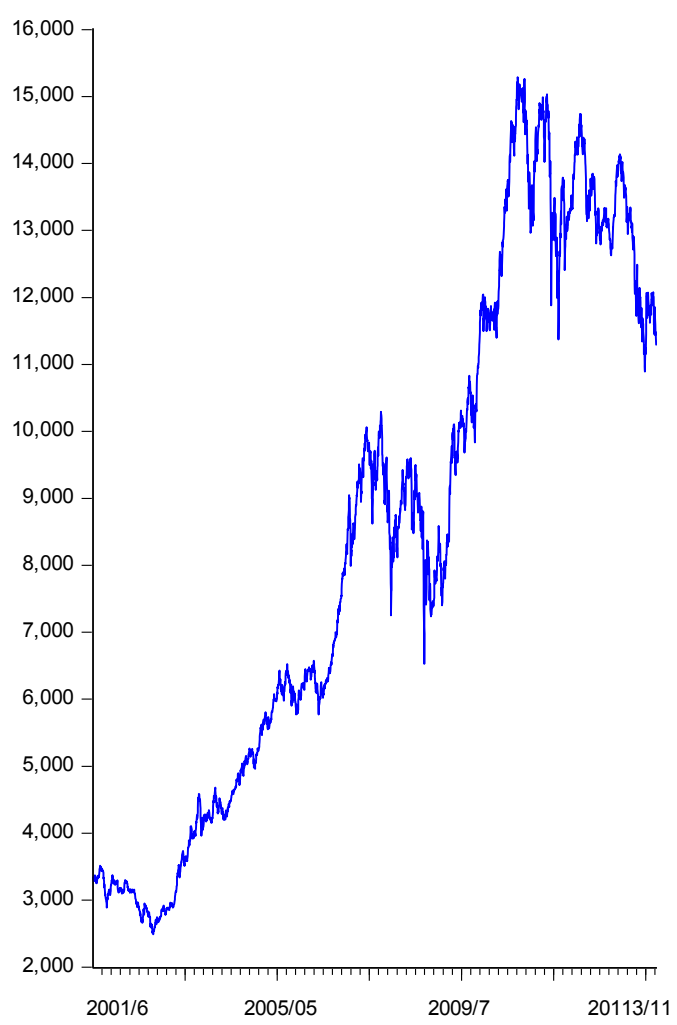

Panel D. Mexico

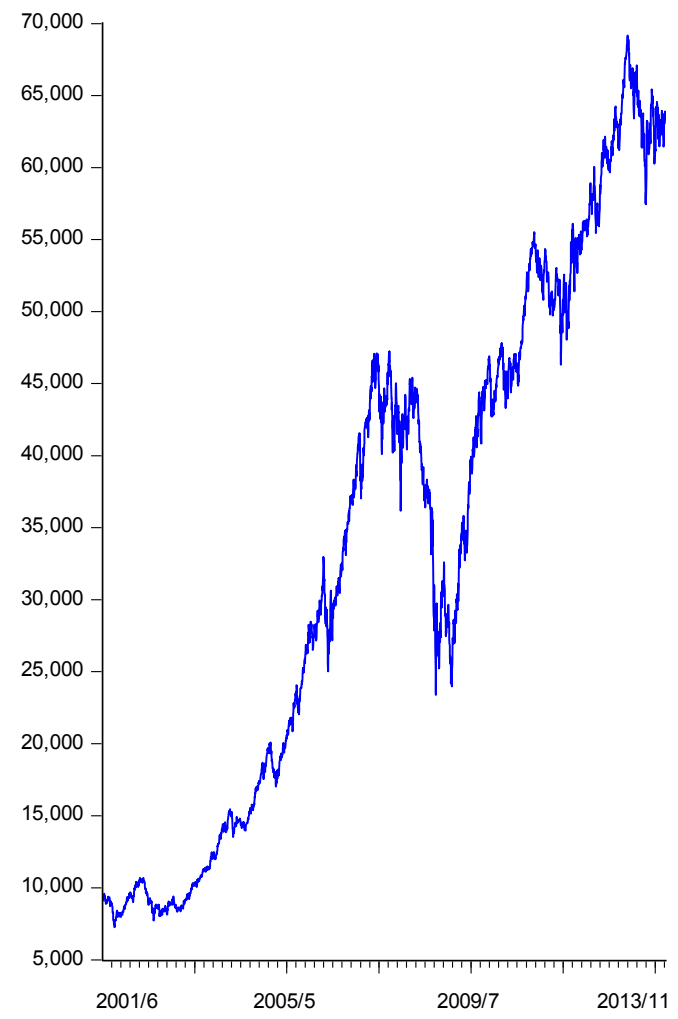

Figure 1. The daily dynamics of the MSCI stock index prices of the countries in Latin America:

The time-series trends from 21 June 2001 to 26 November 2013 
Table 1. Descriptive statistics for the stock returns of the countries in Latin America: Evidence from June 2001 to November 2013

\begin{tabular}{|c|c|c|c|c|}
\hline \multicolumn{5}{|c|}{ Panel A. Daily returns } \\
\hline & Brazil & Chile & Colombia & Mexico \\
\hline Mean & 0.0724 & 0.0463 & 0.1151 & 0.0736 \\
\hline Max & 16.3949 & 18.7958 & 18.8480 & 11.3653 \\
\hline Min & -13.1232 & -7.0997 & -11.3015 & -7.4200 \\
\hline Standrd Deviation & 1.7537 & 1.1197 & 1.4005 & 1.3867 \\
\hline Skewness & 0.2603 & 1.1953 & 0.3943 & 0.2192 \\
\hline Kurtosis & 10.8531 & 32.6479 & 20.2625 & 8.6803 \\
\hline Obs. & 3055 & 3055 & 3055 & 3055 \\
\hline \multicolumn{5}{|c|}{ Panel B. Weekly returns } \\
\hline & Brazil & Chile & Colombia & Mexico \\
\hline Mean & 0.3372 & 0.2214 & 0.5396 & 0.3455 \\
\hline Max & 18.4024 & 18.1306 & 12.1579 & 18.8131 \\
\hline Min & -19.2305 & -20.4679 & -19.3804 & -17.5622 \\
\hline Standrd Deviation & 3.6525 & 2.5750 & 3.0967 & 3.0357 \\
\hline Skewness & -0.2399 & -0.5475 & -0.4854 & -0.1939 \\
\hline Kurtosis & 6.6901 & 13.0796 & 8.3355 & 8.1775 \\
\hline Obs. & 649 & 649 & 649 & 649 \\
\hline \multicolumn{5}{|c|}{ Panel C. Monthly returns } \\
\hline & Brazil & Chile & Colombia & Mexico \\
\hline Mean & 1.4070 & 0.9339 & 2.3757 & 1.4312 \\
\hline Max & 19.4946 & 15.7686 & 20.5411 & 12.8498 \\
\hline Min & -25.0804 & -12.7334 & -21.3756 & -20.0244 \\
\hline Standrd Deviation & 6.6259 & 4.6731 & 6.6914 & 5.1729 \\
\hline Skewness & -0.2711 & 0.1273 & -0.0575 & -0.6681 \\
\hline Kurtosis & 4.1986 & 3.5196 & 4.0088 & 4.3240 \\
\hline Obs. & 149 & 149 & 149 & 149 \\
\hline \multicolumn{5}{|c|}{ Panel D. Quarterly returns } \\
\hline & Brazil & Chile & Colombia & Mexico \\
\hline Mean & 4.4391 & 2.8939 & 7.3585 & 4.4248 \\
\hline Max & 36.3285 & 22.9408 & 42.1552 & 26.6023 \\
\hline Min & -24.6472 & -17.5928 & -22.7243 & -16.7831 \\
\hline Standrd Deviation & 13.3640 & 9.2662 & 13.2684 & 10.3876 \\
\hline Skewness & -0.0582 & 0.0737 & 0.3565 & -0.0190 \\
\hline Kurtosis & 2.8444 & 2.5832 & 3.0281 & 2.2966 \\
\hline Obs. & 50 & 50 & 50 & 50 \\
\hline
\end{tabular}

Notes: This table displays the descriptive statistics for the stock return data in the countries in Latin America. The countries include Brazil, Chile, Colombia, and Mexico. The sample period under our analyses spans from June 2001 to November 2013. In the table, Obs. means the number of the daily, weekly, monthly, and quarterly return data, in order. 
Table 2. The relations between the time-varying risk and return: Evidence from the daily data of four countries in Latin America for the period from June 2001 to November 2013

Panel A. Results of the GARCH-in-mean $(1,1)$ model with conditional variance: Evidence for the period from 21 June 2001 to 26 November 2013

\begin{tabular}{lcccc}
\hline & Constant & $p$-value & $\sigma^{2}$ & $p$-value \\
\hline Brazil & 0.0176 & 0.7332 & 0.0366 & 0.1033 \\
Chile & 0.0468 & 0.1106 & 0.0414 & 0.2351 \\
Colombia & $0.0618^{* * *}$ & 0.0100 & $0.0522^{* * *}$ & 0.0011 \\
Mexico & 0.0557 & 0.1004 & 0.0360 & 0.1319 \\
\hline Positive (negative) significance & \multicolumn{2}{c}{$1(0)$} \\
\hline
\end{tabular}

Panel B. Results of the GARCH-in-mean $(1,1)$ model with conditional standard deviation: Evidence for the period from 21 June 2001 to 26 November 2013

\begin{tabular}{lcccc}
\hline & Constant & $p$-value & $\sigma$ & $p$-value \\
\hline Brazil & -0.1629 & 0.2017 & $0.1833^{* *}$ & 0.0419 \\
Chile & 0.0067 & 0.9172 & 0.0851 & 0.2635 \\
Colombia & -0.0734 & 0.2223 & $0.1903^{* * *}$ & 0.0010 \\
Mexico & -0.0179 & 0.8126 & 0.1104 & 0.1147 \\
\hline Positive (negative) significance & \multicolumn{3}{c}{$2(0)$} \\
\hline
\end{tabular}

Panel C. Results of the EGARCH-in-mean $(1,1)$ model with conditional variance: Evidence for the period from 21 June 2001 to 26 November 2013

\begin{tabular}{lcccc}
\hline & Constant & $p$-value & $\sigma^{2}$ & $p$-value \\
\hline Brazil & -0.0572 & 0.2903 & $0.0516^{* *}$ & 0.0255 \\
Chile & 0.0435 & 0.2067 & 0.0210 & 0.6065 \\
Colombia & $0.0552^{*}$ & 0.0675 & $0.0538^{* *}$ & 0.0153 \\
Mexico & 0.0270 & 0.4377 & 0.0318 & 0.1929 \\
\hline Positive (negative) significance & \multicolumn{2}{c}{$2(0)$} \\
\hline
\end{tabular}

Panel D. Results of the EGARCH-in-mean $(1,1)$ model with conditional standard deviation: Evidence for the period from 21 June 2001 to 26 November 2013

\begin{tabular}{lcccc}
\hline & Constant & $p$-value & $\sigma$ & $p$-value \\
\hline Brazil & $-0.2069^{*}$ & 0.0838 & $0.1808^{* *}$ & 0.0316 \\
Chile & 0.1000 & 0.1121 & -0.0467 & 0.5222 \\
Colombia & -0.0207 & 0.7682 & $0.1376^{* *}$ & 0.0390 \\
Mexico & 0.0238 & 0.7315 & 0.0395 & 0.5406 \\
\hline Positive (negative) significance & \multicolumn{2}{c}{$2(1)$} \\
\hline
\end{tabular}

Notes: This table exhibits the estimation results of several GARCH-in-mean models as to the daily stock return data in the countries in Latin America. The countries include Brazil, Chile, Colombia, and Mexico. The sample period under our analyses spans from June 2001 to November 2013. For the statistical judgments, * means the statistical significance of the coefficients at the $10 \%$ level, ** means the statistical significance of the coefficients at the $5 \%$ level, and $* * *$ means the statistical significance of the coefficients at the $1 \%$ level, respectively. Furthermore, 'Positive (negative) significance' in the table indicates the number of the coefficients that are statistically significantly positive (negative). 
Table 3. The relations between the time-varying risk and return: Evidence from the weekly data of four countries in Latin America for the period from June 2001 to November 2013

Panel A. Results of the GARCH-in-mean $(1,1)$ model with conditional variance: Evidence for the period from June 2001 to November 2013

\begin{tabular}{lcccc}
\hline & Constant & $p$-value & $\sigma^{2}$ & $p$-value \\
\hline Brazil & -0.0629 & 0.8345 & 0.0425 & 0.1203 \\
Chile & 0.0920 & 0.5671 & 0.0343 & 0.2496 \\
Colombia & 0.1253 & 0.5944 & 0.0397 & 0.1555 \\
Mexico & 0.1768 & 0.4039 & 0.0374 & 0.2024 \\
\hline Positive (negative) significance & \multicolumn{2}{c}{$0(0)$} & & $0(0)$ \\
\hline
\end{tabular}

Panel B. Results of the GARCH-in-mean $(1,1)$ model with conditional standard deviation: Evidence for the period from June 2001 to November 2013

\begin{tabular}{lcccc}
\hline & Constant & $p$-value & $\sigma$ & $p$-value \\
\hline Brazil & -0.9228 & 0.1910 & $0.4112^{*}$ & 0.0633 \\
Chile & -0.0258 & 0.5157 & 0.2389 & 0.1915 \\
Colombia & -0.5011 & 0.2873 & $0.3392^{* *}$ & 0.0460 \\
Mexico & -0.2001 & 0.6948 & 0.2488 & 0.2157 \\
\hline Positive (negative) significance & \multicolumn{3}{c}{$2(0)$} \\
\hline
\end{tabular}

Panel C. Results of the EGARCH-in-mean $(1,1)$ model with conditional variance: Evidence for the period from June 2001 to November 2013

\begin{tabular}{lcccc}
\hline & Constant & $p$-value & $\sigma^{2}$ & $p$-value \\
\hline Brazil & -0.2093 & 0.5223 & 0.0461 & 0.1318 \\
Chile & 0.1163 & 0.4776 & 0.0214 & 0.5191 \\
Colombia & 0.1654 & 0.4453 & 0.0383 & 0.1655 \\
Mexico & 0.1973 & 0.3412 & 0.0192 & 0.5291 \\
\hline Positive (negative) significance & \multicolumn{2}{c}{$0(0)$} \\
\hline
\end{tabular}

Panel D. Results of the EGARCH-in-mean $(1,1)$ model with conditional standard deviation: Evidence for the period from June 2001 to November 2013

\begin{tabular}{lcccc}
\hline & Constant & $p$-value & $\sigma$ & $p$-value \\
\hline Brazil & -0.9257 & 0.1903 & $0.3780^{*}$ & 0.0911 \\
Chile & 0.0664 & 0.8524 & 0.0714 & 0.6733 \\
Colombia & -0.2398 & 0.5537 & $0.2576^{*}$ & 0.0881 \\
Mexico & 0.1697 & 0.6905 & 0.0609 & 0.7244 \\
\hline Positive (negative) significance & \multicolumn{2}{c}{$2(0)$} \\
\hline
\end{tabular}

Notes: This table exhibits the estimation results of several GARCH-in-mean models as to the weekly stock return data in the countries in Latin America. The countries include Brazil, Chile, Colombia, and Mexico. The sample period under our analyses spans from June 2001 to November 2013. For the statistical judgments, * means the statistical significance of the coefficients at the $10 \%$ level, $* *$ means the statistical significance of the coefficients at the $5 \%$ level, and $* * *$ means the statistical significance of the coefficients at the $1 \%$ level, respectively. Furthermore, 'Positive (negative) significance' in the table indicates the number of the coefficients that are statistically significantly positive (negative). 
Table 4. The relations between the time-varying risk and return: Evidence from the monthly data of four countries in Latin America for the period from June 2001 to November 2013

Panel A. Results of the GARCH-in-mean $(1,1)$ model with conditional variance: Evidence for the period from June 2001 to November 2013

\begin{tabular}{lcccc}
\hline & Constant & $p$-value & $\sigma^{2}$ & $p$-value \\
\hline Brazil & $3.1219^{* * *}$ & 0.0000 & $-0.0265^{*}$ & 0.0986 \\
Chile & 7.0701 & 0.1121 & -0.2949 & 0.1816 \\
Colombia & 110.3547 & 0.9044 & -2.4901 & 0.9073 \\
Mexico & 0.6835 & 0.3598 & 0.0323 & 0.2995 \\
\hline Positive (negative) significance & \multicolumn{2}{c}{$0(1)$} \\
\hline
\end{tabular}

Panel B. Results of the GARCH-in-mean $(1,1)$ model with conditional standard deviation: Evidence for the period from June 2001 to November 2013

\begin{tabular}{lcccc}
\hline & Constant & $p$-value & $\sigma$ & $p$-value \\
\hline Brazil & -1.8182 & 0.5766 & 0.4934 & 0.3388 \\
Chile & 13.8805 & 0.2052 & -2.8392 & 0.2393 \\
Colombia & 10.9085 & 0.3849 & -1.3058 & 0.4959 \\
Mexico & -0.2846 & 0.8446 & 0.3708 & 0.2380 \\
\hline Positive (negative) significance & \multicolumn{3}{c}{$0(0)$} \\
\hline
\end{tabular}

Panel C. Results of the EGARCH-in-mean $(1,1)$ model with conditional variance: Evidence for the period from June 2001 to November 2013

\begin{tabular}{lcccc}
\hline & Constant & $p$-value & $\sigma^{2}$ & $p$-value \\
\hline Brazil & 1.4926 & 0.1853 & -0.0041 & 0.8812 \\
Chile & $4.3025^{*}$ & 0.0682 & -0.1595 & 0.1785 \\
Colombia & 100.0148 & 0.7763 & -2.2203 & 0.7887 \\
Mexico & 0.6510 & 0.3534 & 0.0341 & 0.3034 \\
\hline Positive (negative) significance & & & & $0(0)$
\end{tabular}

Panel D. Results of the EGARCH-in-mean $(1,1)$ model with conditional standard deviation: Evidence for the period from June 2001 to November 2013

\begin{tabular}{lcccc}
\hline & Constant & $p$-value & $\sigma$ & $p$-value \\
\hline Brazil & 4.0391 & 0.1238 & -0.4048 & 0.3452 \\
Chile & 7.6216 & 0.1203 & -1.4601 & 0.1845 \\
Colombia & 150.9953 & 0.8167 & -22.4372 & 0.8219 \\
Mexico & -0.3388 & 0.8071 & 0.3830 & 0.2288 \\
\hline Positive (negative) significance & & $0(0)$ & & $0(0)$
\end{tabular}

Notes: This table exhibits the estimation results of several GARCH-in-mean models as to the monthly stock return data in the countries in Latin America. The countries include Brazil, Chile, Colombia, and Mexico. The sample period under our analyses spans from June 2001 to November 2013. For the statistical judgments, * means the statistical significance of the coefficients at the $10 \%$ level, $* *$ means the statistical significance of the coefficients at the $5 \%$ level, and $* * *$ means the statistical significance of the coefficients at the $1 \%$ level, respectively. Furthermore, 'Positive (negative) significance' in the table indicates the number of the coefficients that are statistically significantly positive (negative). 
Table 5. The relations between the time-varying risk and return: Evidence from the quarterly data of four countries in Latin America for the period from June 2001 to November 2013

Panel A. Results of the GARCH-in-mean $(1,1)$ model with conditional variance: Evidence for the period from the third quarter of 2001 to the fourth quarter of 2013

\begin{tabular}{lcccc}
\hline & Constant & $p$-value & $\sigma^{2}$ & $p$-value \\
\hline Brazil & $1.4195^{* * *}$ & 0.0000 & $0.0200^{* * *}$ & 0.0000 \\
Chile & $8.4250^{* * *}$ & 0.0000 & $-0.0545^{* * *}$ & 0.0002 \\
Colombia & $-34.2590^{*}$ & 0.0658 & $0.3013^{* * *}$ & 0.0018 \\
Mexico & -0.0656 & 0.9732 & $0.0398^{* *}$ & 0.0224 \\
\hline Positive (negative) significance & \multicolumn{2}{c}{$3(1)$}
\end{tabular}

Panel B. Results of the GARCH-in-mean $(1,1)$ model with conditional standard deviation: Evidence for the period from the third quarter of 2001 to the fourth quarter of 2013

\begin{tabular}{lcccc}
\hline & Constant & $p$-value & $\sigma$ & $p$-value \\
\hline Brazil & $13.7765^{* * *}$ & 0.0000 & $-0.7073^{* * *}$ & 0.0000 \\
Chile & $8.3902^{* * *}$ & 0.0004 & $-0.7402^{* * *}$ & 0.0095 \\
Colombia & $-80.1422^{* *}$ & 0.0322 & $7.4223^{* * *}$ & 0.0066 \\
Mexico & $-31.8021^{* * *}$ & 0.0000 & $2.5667^{* * *}$ & 0.0000 \\
\hline Positive (negative) significance & \multicolumn{2}{c}{$2(2)$} \\
\hline
\end{tabular}

Panel C. Results of the EGARCH-in-mean $(1,1)$ model with conditional variance: Evidence for the period from the third quarter of 2001 to the fourth quarter of 2013

\begin{tabular}{lcccc}
\hline & Constant & $p$-value & $\sigma^{2}$ & $p$-value \\
\hline Brazil & $2.0793^{* * *}$ & 0.0000 & $0.0262^{* * *}$ & 0.0035 \\
Chile & $5.6824^{* * *}$ & 0.0000 & $-0.0392^{*}$ & 0.0982 \\
Colombia & $5.3633^{* *}$ & 0.0195 & 0.0121 & 0.5177 \\
Mexico & -59.7892 & 0.1678 & $0.7048^{*}$ & 0.0502 \\
\hline Positive (negative) significance & \multicolumn{2}{c}{$2(1)$} \\
\hline Panel D. Results of the EGARCH-in-mean (1,1) model with conditional standard deviation: Evidence for the \\
period from the third quarter of 2001 to the fourth quarter of 2013 \\
\hline \multicolumn{7}{c}{$p$-value } & $\sigma$ & $p$-value \\
\hline Brazil & Constant & 0.3438 & $0.5125^{* * *}$ & 0.0003 \\
Chile & 0.7356 & 0.0003 & $-0.6418^{* *}$ & 0.0420 \\
Colombia & $7.7977^{* * *}$ & 0.6374 & $0.8469^{*}$ & 0.0907 \\
Mexico & -2.3480 & 0.1663 & 11.9927 & 0.1005 \\
\hline Positive (negative) significance & -110.1384 & $1(0)$ & \multicolumn{2}{c}{$2(1)$} \\
\hline
\end{tabular}

Notes: This table exhibits the estimation results of several GARCH-in-mean models as to the quarterly stock return data in the countries in Latin America. The countries include Brazil, Chile, Colombia, and Mexico. The sample period under our analyses spans from June 2001 to November 2013. For the statistical judgments, * means the statistical significance of the coefficients at the $10 \%$ level, $* *$ means the statistical significance of the coefficients at the $5 \%$ level, and $* * *$ means the statistical significance of the coefficients at the $1 \%$ level, respectively. Furthermore, 'Positive (negative) significance' in the table indicates the number of the coefficients that are statistically significantly positive (negative).

\section{Empirical Results}

This section documents our empirical results. First, we exhibit the estimation results of our models (1) to (4) from Tables 2 to 5 . More concretely, Tables 2 to 5 show the estimation results from our daily data, weekly data, monthly data, and quarterly data, respectively.

Describing the results in short, as to the overall results, the numbers of the statistically significant positive GARCH 
and EGARCH-in-mean parameters are 7 for daily data, 4 for weekly data, 0 for monthly data, and 9 for quarterly data, as seen in Tables 2 to 5 , respectively. Further, the numbers of the statistically significant negative GARCH and EGARCH-in-mean parameters are 0 for daily data, 0 for weekly data, 1 for monthly data, and 5 for quarterly data, respectively, also as shown in Tables 2 to 5. Describing the evidence from another angle, according to Tables 2 to 5 , we understand that the numbers of the statistically significant positive GARCH and EGARCH-in-mean parameters are 8 for Brazil, 0 for Chile, 9 for Colombia, and 3 for Mexico, respectively. Moreover, as recognized from Tables 2 to 5, the numbers of the statistically significant negative GARCH and EGARCH-in-mean parameters are 2 for Brazil, 4 for Chile, 0 for Colombia, and 0 for Mexico, respectively. We here emphasize that it is interesting that in the Latin American equity markets, where upward stock market trends are recently recorded, strictly robust evidence of the positive risk-return relationship cannot always be found. Further, it is also interesting that in Chile, no positive risk-return relationship is observed as above.

Furthermore, inspecting the values of returns in Table 1, mean returns in Chile always take the smallest values in all data frequencies. In addition, mean return volatilities in Chile also always take the smallest values for all data frequencies. On the other hand, in Table 1, mean returns in Colombia always take the highest values for all data frequencies. In addition, mean return volatilities in Colombia take relatively high values for all data frequencies. These tendencies may lead our evidence that, in the equity market in Chile, no risk-return tradeoff is observed while the market in Colombia, risk-return tradeoff is more frequently observed.

\section{Conclusions and Several Perspectives}

This paper examined the risk and return relationship in the Latin American equity markets. We found that the linkage between risk and return were relatively positive although it was not always. The implications and perspectives from our studies are as follows. First, (1) as to the data frequency, from the practical point of view, quarterly or yearly data would be more important for using the states of the risk-return relations of equity markets for the real-world analyses. Our results by using quarterly data indicated relatively strong positive risk-return relations, thus, further tests by using the quarterly or yearly data of longer periods would be also useful. Second, (2) for the empirical tests, the results seem to depend on the models employed, thus empirical tests by using several models and by altering or adjusting their model specifications shall be more effective; this kind of analyses would always entail the so-called model risk. Nevertheless, it is interesting that strictly robust evidence of the positive risk-return relationship could not necessarily be found in the recent upward Latin American equity markets. Hence it is important for us to watch the real-data and stock market trends in all over the world continuously. Further research by using longer data of several kinds of data frequencies for international equity markets shall be also one of our future tasks.

\section{Acknowledgements}

I thank the Japan Society for the Promotion of Science for their kind financial support for my research. Further, I greatly thank the repeated kind invitation from the journal to write to this journal. Moreover, I also thank the Editor and anonymous referees for their comments on this paper. Finally, I greatly appreciate the Editor for the quick decision to my paper.

\section{References}

Baillie, R. T., \& DeGennaro, R. P. (1990). Stock returns and volatility. Journal of Financial and Quantitative Analysis, 25, 203-214. http://dx.doi.org/10.2307/2330824

Campbell, J. Y. (1987). Stock returns and the term structure. Journal of Financial Economics, 18, 373-399. http://dx.doi.org/10.1016/0304-405X(87)90045-6

French, K. R., Schwert, G. W., \& Stambaugh, R. F. (1987). Expected stock returns and volatility. Journal of Financial Economics, 19, 3-29. http://dx.doi.org/10.1016/0304-405X(87)90026-2

Ghysels, E., Santa-Clara, P., \& Valkanov, R. (2005). There is a risk-return trade-off after all. Journal of Financial Economics, 76, 509-548. http://dx.doi.org/10.1016/j.jfineco.2004.03.008

Glosten, L. R., Jagannathan, R., \& Runkle, D. E. (1993). On the relation between expected value and the volatility of the nominal excess return on stocks. Journal of Finance, 48, 1779-1801. http://dx.doi.org/10.1111/j.1540-6261.1993.tb05128.x

Harvey, C. R. (1991). The World Price of Covariance Risk. Journal of Finance, 46, 111-157. http://dx.doi.org/10.1111/j.1540-6261.1991.tb03747.x

Lundblad, C. (2007). The risk return tradeoff in the long run: 1836-2003. Journal of Financial Economics, 85, 123-150. http://dx.doi.org/10.1016/j.jfineco.2006.06.003

Whitelaw, R. (1994). Time variations and covariations in the expectations and volatility of stock market returns. Journal of Finance, 49, 515-541. http://dx.doi.org/10.1111/j.1540-6261.1994.tb05150.x 